\title{
Family Conflict - The Major Underlying Influence in Suicide Attempts in Northern Bihar, India.
}

\author{
Sangeeta Nair ${ }^{a}$, Lois Joy Armstrong ${ }^{b}$, Philip Finny ${ }^{c}$ \\ ${ }^{a}$ Clinical Psychologist, Department of Medicine, Duncan Hospital, A unit of Emmanuel Hospital Association \\ ${ }^{\mathrm{b}}$ Research Co-ordinator, Epidemiology and Research Dept, Duncan Hospital, A unit of Emmanuel Hospital Asso- \\ ciation \\ ${ }^{\mathrm{c}}$ Consultant Physician/Endocrinologist, Duncan Hospital, A unit of Emmanuel Hospital Association
}

\section{Abstract}

Suicide attempts in North India are generally underreported but have been considered to be rising. The number of admissions due to attempted suicide at Duncan Hospital, North Bihar, rose from 82 in 2007 to 419 in 2011.

A structured interview and the WHO (World Health Organization) Major (ICD-10) Depression Inventory were completed by 157 suicide-attempt survivors. Immediate relatives were also interviewed. Only $23 \%$ of patients came from India; $77 \%$ of patients came from Nepal. The highest incidence was in the age group 1620 years. Females have higher rates in the $21-30$ year age group $(p=0.012)$, but after 30 years of age, the number of males becomes higher than the females $(p=0.048) ; 81.5 \%$ of the respondents were below the age of 30 years.

Pesticide poisoning was the major mode of attempted suicide (94.3\%). Using the WHO Major (ICD-10) Depression Inventory, 28 of the participants suffered from depression (17.7\%). Ninety people (56.9\%) admitted to previous thoughts of suicide, and nine (5.7\%) people had attempted suicide previously.

Hindus made up $84.0 \%$ of the respondents. Almost $50 \%$ of respondents only carried out their religious rituals on an occasional basis or not at all. $70.2 \%$ had not completed education beyond primary school, and $49.7 \%$ earned less than Rs 10,000 per month (US\$200). Eighty percent of the participants stated conflicts with family members led to the attempted suicide. Relatives did not expect the attempted suicide in $97.4 \%$ of cases. Knowledge of the suicide of a neighbour, friends, or relative influenced $77.0 \%$ of the participants to attempt suicide.

Efforts to prevent suicide attempts and deaths need to be multifaceted. Banning the most poisonous pesticides and improving poison storage in the community must be encouraged. Prevention, early intervention and treatment all are required in a suicide prevention plan. The lack of psychiatrists necessitates that other professionals and trained non-professionals be utilised in the mental health team. Holistic care should include cultural aspects like shame as well as physical, psychosocial, and spiritual issues. Special interventions need to be aimed at training adolescents in stress management and conflict resolution and mentoring adolescents to become part of strong, caring families. 


\section{Introduction}

Suicide is a worldwide phenomenon, and whether it is a fatal or non-fatal suicide attempt, it has repercussions on the family, the extended family, and wider community. India is no exception. Shame has always been associated with suicide, but in cultures where shame and honour play a larger cultural role than in the Western world, suicide has its own unique characteristics. It leads to the problem of suicide being hidden and underestimated. This is especially so in the teeming millions of North India.

The state of Bihar had a population of 104 million in the 2011 census and a population density of 1100 people per square kilometre. ${ }^{1}$ With the current $25 \%$ growth rate, this is now much higher. ${ }^{1}$ Bihar is on the fertile Gangetic plain and has an $89 \%$ rural population, predominantly farmers. ${ }^{1}$ Although productive farming land, it is prone to flooding because of the many rivers running down from Nepal, across the plain, and into the Ganges River. The religion figures from the 2011 census are not yet available, but in the 2001 census, Hindus made up $79 \%$ of the population of Bihar followed by $16.5 \%$ Muslims and $0.064 \%$ Christians. $^{2}$

In rural Bihar, the literacy rate is $59.78 \%$ with female literacy lagging behind at $44.3 \%$. ${ }^{1}$ The figure for the timely completion of primary school education for the state is $23 \% .^{3}$ Only $21 \%$ of primary school teachers had completed tenth standard of education. ${ }^{3}$ Bihar follows Uttar Pradesh in being the state with the second largest number of people below the poverty line. However, as a percentage of the population, Bihar is the highest. ${ }^{4}$ In East Champaran District where Duncan Hospital is located, $21.3 \%$ of people have access to electricity, 93.5\% use firewood/crop residue/cow dung as fuel for cooking, $61.2 \%$ have a phone/mobile phone, and $8.8 \%$ possess a computer. ${ }^{5}$ It is these types of figures, along with a history of poor administration and law enforcement, which have given Bihar the reputation of being the most backward state in the country.
In general, health facilities in Bihar are severely under resourced. ${ }^{6,7}$ The number of psychiatrists per 100,000 population has been studied, and, overall, India has a $77 \%$ deficit in the number of psychiatrists. Bihar is the third most badly serviced state with a deficit of $96.62 \% .^{8}$ At the time of the study, there were no psychiatrists in the District of East Champaran (5 million people) and no evidence of a District Mental Health Plan.

In India, there are many reports of rising suicides and particularly high rates reported in the affluent states of India such as Kerala and Tamil Nadu. ${ }^{9-11}$ In Maharashtra and Andhra Pradesh, farmer suicides are a particular problem and frequently relate to financial crises. ${ }^{12}$ In North India, especially Bihar, there is little data, and lack of reporting may be influencing the reported low rates in these regions. ${ }^{13}$

Around the world, there are many reports of rural suicide rates being higher than urban. Some of the reasons given are the instability of farming income due to climate change and natural disasters, increased access to pesticides and firearms, social isolation, higher population of indigenous communities, and decreased access to health care and, specifically, psychiatric care. $^{14-16}$

In India, Radhakrishnan reports urban suicides to be higher than rural, using National Crime Records Bureau (NCRB) data, with the reasons given being social isolation and overcrowding. ${ }^{17}$ In the Million Death Study, rural suicides are reported to be higher than urban with the reasons suggested to be higher availability of pesticides and poorer access to medical care. ${ }^{18}$ The discrepancy between these two Indian reports may be that there are poorer reporting systems in rural India.

Duncan Hospital is a 230 bed hospital and community health facility at Raxaul, East Champaran District, Bihar. It began in 1930 on the Indo-Nepal border to serve patients from both India and Nepal. It is a secondary level referral centre with basic specialities and is part of the larger Non-Governmental Organisation, 
Emmanuel Hospital Association. At the time of the study, there were two physicians who took a special interest in mental health and a clinical psychologist.

Duncan Hospital recorded 82, 126 and 202 admissions due to attempted suicide in the years 2007, 2008, and 2009. Of these 410 patients, 403 patients ingested poisons (predominantly pesticides), and seven attempted hanging (Unpublished hospital data). An audit of poisoning cases was carried out from 1 February 2011 to 31 January 2012 that included 418 attempted suicides by poisoning and one attempted hanging. These poisoning cases constituted $9.5 \%$ of all the medical inpatients. Of those who took poisons, $9.5 \%$ died due to fatal complications. The age group with the highest frequency was 16-20 years, and there were slightly more females than males $(52.1 \%$ : 47.9). (Unpublished hospital data)

After collecting a year of clinical data, expanded understanding of the psychological and sociological issues involved in attempted suicide in this region was needed. Current literature seems to have variation across the country regarding influencing factors, and as there was no published literature from this region, we hoped to determine what factors were relevant for North Bihar. The aim of this was to help us develop relevant hospital and community services with appropriate personnel to treat mental health issues and prevent suicides.

\section{Materials and Methods}

Patients admitted to Duncan Hospital for attempted suicide were interviewed by a clinical psychologist (MA[Clinical Psychology], MSc[Applied Psych]). These interviews were carried out after medical treatment was completed and verbal consent obtained from the patient. Verbal consent was used because of the sensitivity of the issue and a reluctance of people to talk if written consent was required. Patients who did not survive or were discharged early or against medical advice were unable to be interviewed. One or two close relatives of the patient were also interviewed. At the time of the interview, the psychologist also provided counselling for the patient and their relatives.

Patient and close relative interviews were done using a questionnaire looking at demographic and socio-economic factors and a series of questions related to social factors and reasons for suicide. The WHO Major (ICD-10) Depression inventory was also completed to assess for depression among the attempted suicide cases. ${ }^{19}$ The Beck Depression Inventory was pilot tested, but was found to be too difficult to be used due to the complexity of ideas and words used.

The data from the questionnaire was coded and put in MS Excel and analyzed. Vassarstats Online was used for obtaining $p$ values for differences of proportions and for confidence intervals. ${ }^{20} \quad 95 \%$ two-tailed measurements were applied. Approval for this study was obtained from Emmanuel Hospital Association Research and Ethics Committee (Proposal Number 80).

\section{Results}

Between 16 May 2012 and 13 March 2013, there were 372 suicide attempts (368 poisonings and 4 hangings) of which 32 persons died in hospital. One hundred and fifty-eight of these suicide-attempt survivors were approached for interview. One interview was not completed due to problems with language. One psychologist was available to conduct the interviews during regular working hours. Although attempts were made to keep people for interview and counselling, many left prior to being seen.

\section{Demographic data}

$77.7 \%$ of the patients came from Nepal $(\mathrm{n}=122)$ with the remainder, $22.3 \%$, being from India $(n=36)$. Females $(n=85,54.1 \%)$ presented more often than males $(n=73$, $45.9 \%)$. 
The highest incidence in the 5-year age interval was 16-20 years. Gender ratio changes through the age groups. No significant difference exists under the age of $20(\mathrm{p}=0.26)$, but in the 21-30 age group, females predominate $(\mathrm{p}=0.012)$. After 30 years of age there are significantly more males than females. $(p=0.048) . \quad 81.5 \%$ of the respondents were below the age of 30 years. (Figure 1)

Figure 1. Age interval and gender of suicide attempt patients

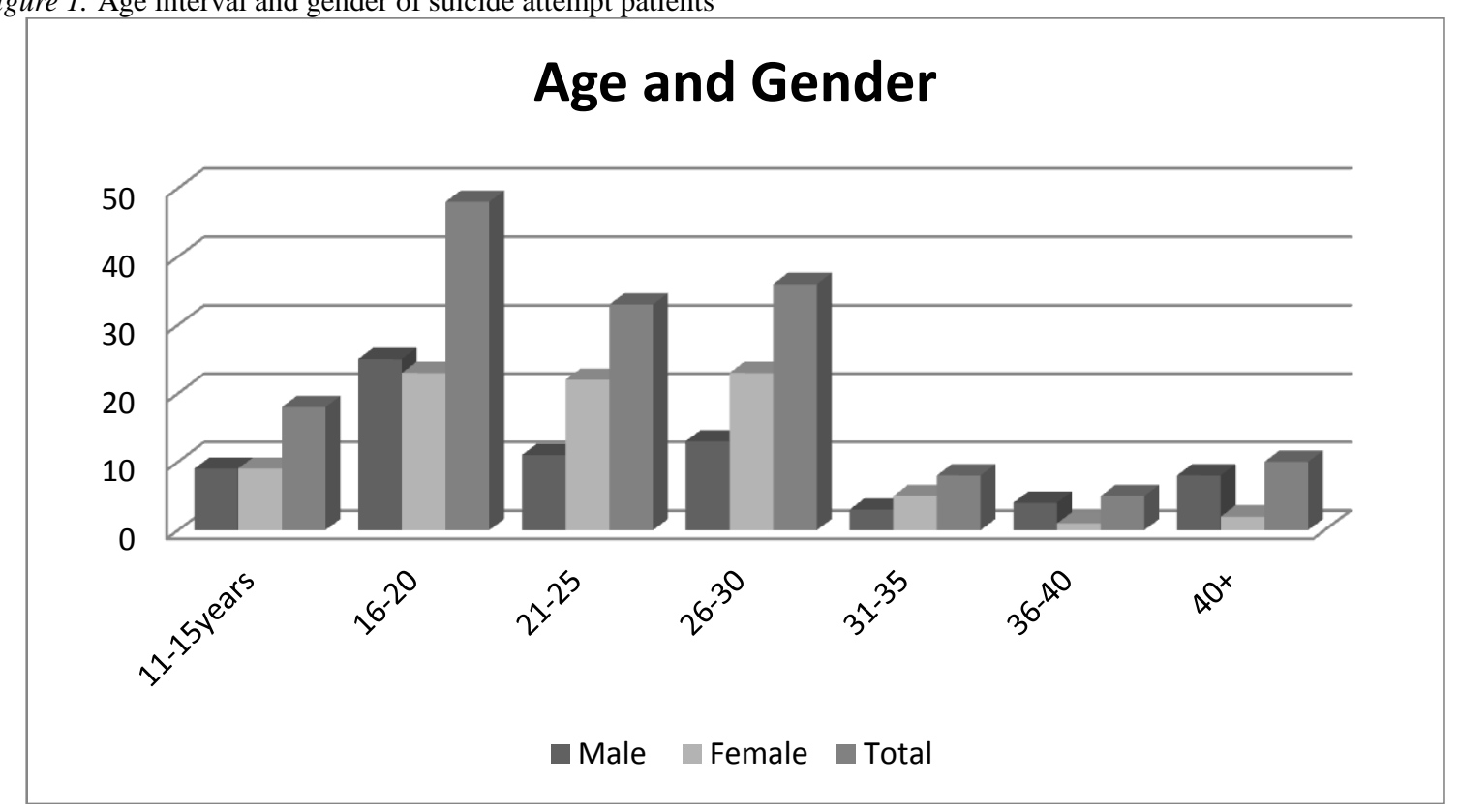

$71.5 \%$ of the respondents were married $(n=56)$, and $1.8 \%$ (students) were living away $(n=113) .63 .7 \%$ respondents were living in joint from home $(n=2)$. families $(n=100), 35.7 \%$ in nuclear families

Figure 2. Education completion

\section{Education completion}

Number of respondents

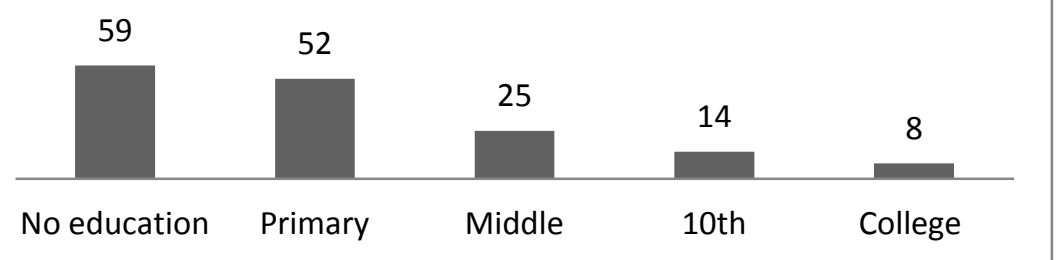

One hundred and twelve of our respondents had not completed primary education (70.2\%). The most common occupation was housewife $(n=59,37.6 \%)$. Students were the second largest group $(n=34$,
21.6\%). Male respondents had a variety of occupations, the top three being: agriculture workers $(n=18,11.5 \%)$, skilled labourers $(n=14$, $8.9 \%)$, and business owners $(n=13,8.3 \%)$. (Figure 2) 
Figure 3. Occupation of Respondents

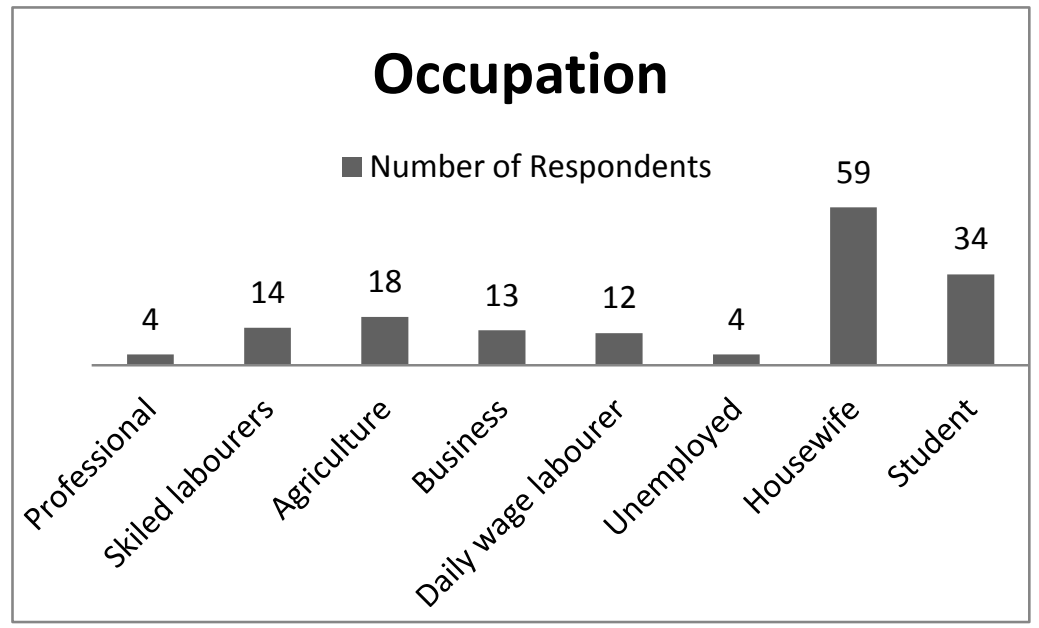

$49.7 \%$ of respondents had a monthly income of 10,000 Indian Rupees [US\$200] or less $(n=78)$. 27.4\% earned between 10,00019,999 Indian Rupees [US\$200-400] per month $(n=43)$, and $9.5 \%$ earned above 20,000 Indian Rupees [US\$400] per month ( $n=15)$. $14.0 \%$ of respondents, mostly women, did not know their average monthly income $(\mathrm{n}=22) .9 .5 \%$ of respondents said they had debt $(\mathrm{n}=15)$. (Fig 3)

Hindus made up $84.0 \%$ of the participants $(\mathrm{n}=132)$. Muslims were $15.2 \%(\mathrm{n}=24)$ and $1.3 \%$ of the group $(\mathrm{n}=2)$ were Buddhist. Frequency of practice of religious rituals varied, with $38.2 \%$ who practiced them daily $(n=60)$ and $14.0 \%$, two to three times per week $(n=22)$. $30.6 \%$ practiced their religious rituals only at major festivals $(n=48)$, and $17.8 \%$ did not practice them at all $(n=28)$. Women were more likely to practice their religion than men; of those who never practiced their religion, $67.8 \%$ were male, and of those who practised their religion daily, $70.0 \%$ were female. When asked about how meaningful/helpful their religious practices were to them, $17.2 \%$ said it was very meaningful $(\mathrm{n}=27), \quad 59.2 \%$ said somewhat helpful ( $\mathrm{n}=93)$, and $24.0 \%$ said it was not helpful at all $(\mathrm{n}=38)$.

\section{Suicide Incident Data}

Of the interview population, 148 attempted suicide by ingestion of poison, usually pesticide (94.3\%), nine respondents took an overdose of medication (5.7\%), and one attempted hanging $(0.63 \%)$.

Table 1: Stated reasons for attempting suicide

\begin{tabular}{lll}
\hline Reasons for attempting suicide & Total & \% with 95\% CI \\
\hline Conflict between husband \& wife & 52 & $32.9(26.1-40.1)$ \\
Conflict with other family members & 47 & $29.7(23.17-37.3)$ \\
Conflict with in laws & 27 & $17.1(12.0-23.7)$ \\
Suspicion of extramarital affair & 10 & $6.3(12.0-23.7)$ \\
Insult & 4 & $2.5(0.99-6.33)$ \\
Exam failure & 3 & $1.9(0.65-5.43)$ \\
Did not reveal reason & 3 & $1.9(0.65-5.43)$ \\
Under influence of alcohol & 3 & $1.9(0.65-5.43)$ \\
Forced marriage & 2 & $1.27(0.35-4.5)$ \\
Bereavement of family member & 2 & $1.27(0.35-4.5)$ \\
Lost large amount of money & 1 & $0.63(0.11-3.5)$ \\
Sickness/anxiety & 1 & $0.63(0.11-3.5)$ \\
Neighbor suggested her that her husband was & 1 & $0.63(0.11-3.5)$ \\
going to remarry & & \\
Total & 157 & \\
\hline
\end{tabular}


One hundred and twenty of the respondents stated that a family conflict was the reason they had attempted suicide (80.2\%). This includes spouse, in-laws, and other family members. (Table 1). When the issue of family conflict was separated according to gender, women had significantly more problems with family conflict than men $(\mathrm{p}=0.0042)$. On sub group analysis, it was also noted that conflict with in-laws was more for women $(\mathrm{p}=0.001)$ while conflict with other family members was significantly more for the men $(\mathrm{p}=0.0004)$. Conflict in marriage was also more for women than men but was not statistically significant $(\mathrm{p}=0.22)$.

Of the people who were married, $25.9 \%$ reported they had a poor relationship with their spouse, and $28.7 \%$ reported they had a poor relationship with their in-laws. $36.9 \%$ of respondents felt that they were harassed $(n=58)$, and $7.5 \%$ of respondents stated alcohol was a cause of quarrelling in the home more than twice a week $(n=12)$.

\section{Mental health}

Using the WHO Major (ICD10) Depression Inventory, it was observed that $17.7 \%$ of the respondents were suffering from depression $(n=28)$. Nine met the criteria of mild depression, nine of moderate depression, and ten of severe depression. Assessment by the medical team found two participants who were psychotic. Eleven people stated they had chronic medical illnesses (7.0\%). Nine respondents had attempted suicide previously (5.7\%), and 90 participants admitted to having previous suicidal thoughts $(57.3 \%)$.

One hundred and twenty-one of the respondents were influenced to attempt suicide because of having heard about someone in their neighbourhood, friends, or family who had previously attempted suicide (77.0\%). Six were influenced by the television (3.8\%), and thirtyone did not know what influenced them (19.6\%).

\section{Response by the relatives}

One or two close relatives of the respondents were also interviewed using a structured questionnaire. $97.4 \%$ of the relatives stated that the news about the person attempting suicide was unexpected. Fourteen relatives did not want to continue with the questionnaire at this point $(8.9 \%)$. Seven relatives had noted some clues that the person might consider suicide, $(4.4 \%)$ and four had heard some expression of suicidal thoughts (2.5\%). Thirty-nine of the relatives had noted the person who attempted suicide had been sad in the previous few days (24.8\%).

\section{Discussion}

\section{Demographics and Socio economics}

Over $80 \%$ of the suicide attempt respondents in this study were under 30 years of age. Although this finding is similar to the Million Death Study of suicides in India, where $70 \%$ of the suicides deaths were in the 16 to 30 age group, an even larger percentage in the under 30 age group is described here. ${ }^{18}$ Although the 1620 age group had the highest rates, there were more cases in the 21-30 age group than the 1120 age group. Although our data is on suicideattempt survivors rather than deaths, it highlights the impact made on this economically productive age group.

The very high rates in the $16-20$ year age group are of great concern as is the fact we also have had suicide attempts down to 10 years of age. Aaron et al in Tamil Nadu also had their highest rates in the 10-19 year age group. ${ }^{12}$ In Bihar, the majority of young people leave school early, begin working at a young age, and get married as early as thirteen years of age. They are forced to take on the challenges of complex life situations in their early teens before they develop adult logical thinking skills.

Data relating to age and gender varies throughout India, according to whether suicides or suicide attempts are being measured. ${ }^{21,22}$ The Million Death Study reported more deaths for men than women, but the average age at which 
the suicide attempt occurs is younger for women than for men. ${ }^{18}$. This has been in a number of other studies as well. ${ }^{21,22}$ Other researchers have used age intervals rather than average age, perhaps due to the fact that many Indians do not know their age accurately. However, the common finding of higher rates for women in the 1530 age group and higher rates for men over the age of 30 , as in the data of this study, would be another way of expressing the same phenomena. $^{10,23}$

Some of the reasons given for the high number of suicides in young women concern marriage issues: arranged marriages, dowry, adjustment of moving to the husband's home, infertility, unable to produce a boy child, domestic violence, harassment by in-laws, and the pressure to stay in an unhappy marriage. ${ }^{17,21}$ Another reason might be that women have very little voice in decision making in many of these issues.

Given the age of the respondents in this study, most should have completed primary education. The fact that $70.2 \%$ had not completed any education beyond primary level education highlights that respondents have very little education. The rate of timely completion of primary school in Bihar is $25 \%$ which compares well to the study data seen here. ${ }^{3}$ Lack of education decreases the options which a person is able to access when looking for support in times of crisis.

Fifty-two percent of the respondents had an income of less than 10,000 Rupees (US\$200) per month, but, surprisingly, very few people gave lack of finances as their reason for suicide. Lack of finances may have contributed to the family conflict in more situations, but the topic of the conflict was not elicited. The Bihar Department of Agriculture states that $81 \%$ of the workforce is involved in agriculture production while this study has only $11.5 \%$ of respondents who were farmers or farmer labourers. ${ }^{24}$ This proportion is significantly different $(p<0.0002)$, suggesting that farmer suicide is not a major problem in this region.
Exam failure and academics also do not seem to be a major problem for this region. Although $22 \%$ of the respondents were students, only three gave exam failure as their reason for attempting suicide. The general term, family conflict, may hide some cases. Academic pressure was the equal third topic mentioned in the Focus Group Discussions (FGDs) in the qualitative work of the author (Unpublished MA thesis, 2013). There were also a couple of subjects in the study who wanted to study but were not allowed to, or not able to, due to finances.

\section{Family Conflict}

Eighty percent of respondents stated the reason for suicide as conflict within the family. Other studies have recognised this before, but this is the highest rate of family conflict documented. $^{10,17,21,22}$ Family conflict needs to be sensitively explored in further studies to try and understand the reason for the conflict and to find the point where communication breaks down so that one of the parties feels the only way out is to end their life. Manorajitham et al. used the collective term "psychosocial stress" to describe the major risk factor for suicide. ${ }^{25}$ Ongoing family conflict and psychosocial stress may well overlap in these definitions, but the difference in terminology makes it difficult to compare the two studies.

Suicide is frequently considered the only option for a person wanting to leave a family in conflict. Divorce or separation, although permitted, carries with it a huge burden of shame, not just for the individual but for their present family and for their family of origin as well. Shame, plus the lack of facilities such as safe houses or shelters, leaves very few options. Even if a woman leaves her husband's home (where she lives after marriage) and returns to her family home, she will be frequently returned to her husband's home, the place of conflict, to prevent shame for both of the families.

Training adolescents in life skills relating to coping with stress, conflict management, and encouraging healthy family relationships are good preventative measures to be considered. 
An emphasis on forgiveness and reconciliation are two important principles that the Christian faith has to offer in helping people with family conflict.

\section{Mental Health}

Fifty-seven percent of the respondents stated they had had previous suicidal thoughts and ten percent of this group had attempted suicide previously. To the best of our knowledge, no other Indian literature has recorded such high rates of prior suicidal thoughts. Even with this high rate, most relatives of the suicide-attempt survivors found the suicide attempts unexpected. Behaviours suggesting a person might be considering suicide were rarely noticed.

Education about expressed thoughts and behaviours people show, prior to attempting suicide, is a tool for preventing suicide in the Western world. ${ }^{26}$ This could also be used to educate families and lay people in India, but first there needs to be research to ascertain if there is any cultural variation in behaviours which people express when considering suicide in India and whether there might be differences between rural and urban areas.

Psychosis was rare, but $18 \%$ of the respondents had depression according to the WHO Major Depression (ICD-10) inventory. This proportion might have been higher. The psychologist conducting the test found this tool missing some cases of mild depression when compared to clinical assessment. This rate of mental health disorder is similar to what is seen in other parts of India which is between 20-40\%. ${ }^{24,} 27$ These data are different from those reported in Western literature where mental health disorders exist in $91 \%$ of suicide deaths. ${ }^{28}$

The part alcohol contributes to the problem of suicide use may have been underestimated in this study. The Annual Health Survey 2010-2011, Bihar (2012) showed that East Champaran had the highest rate of people habitually drinking alcohol of any district in the state(14.9\%). ${ }^{5}$ One of the authors (Unpublished MA thesis, 2013) found alcohol abuse was frequently mentioned in the FGDs in their study.
The use of a questionnaire may not have been the best way to get people to admit to the use or abuse of alcohol.

The psychologist conducting the WHO ICD-10 inventory found that the language was difficult for people with low literacy to understand, even though it was the simplest tool found.

\section{Religion and Culture}

The proportion of Hindus in this study is higher than the state data, and the number of Muslims is slightly less, but this is not significant $(\mathrm{p}=0.18)$. The fact there are no Christians in the study reflects the low percentage of Christians in this part of India and the larger number of Buddhists reflects the proximity to Nepal where there are more Buddhists.

The three major religions of India, Hinduism, Islam, and Christianity, all teach that suicide (as per the context used here) is not acceptable. Muslims and Christians both say that God is the one who gives life and is the only one entitled to end life. Islam and some parts of the Christian community in India are very strong in declaring that suicide is a sin. The practice of seeing people who attempt suicide as people who need assistance rather than need condemnation also exists among Christians. In Buddhism, there is no clear cut teaching. ${ }^{29}$

Although, at first, it may appear that Hinduism might allow suicide because it simply means going on to the next life, this is not a correct understanding. Human life is seen as the highest form of life and to cut that short would be considered bad karma and would send a person back to a lower form of life. Each cycle of life is allotted a certain amount of time. If this is cut short prematurely, then the person will become ghost/wandering spirit (bhoot) until the allotted time for them to move onto the next life. $^{30}$

Sati, the outlawed practice of a widow joining her dead husband on the funeral pyre, may also be seen as suicide, but the cultural and social issues here are somewhat different. Hinduism does have some acceptable forms of sui- 
cide that are considered self-sacrifice rather than suicide: agnipravesa - offering of the body to fire, prayopravesa - offering of the body to air, and samadhi - offering of the body to the earth. These ascetic religious practices can only be carried out when a person has reached a high level of spirituality and has no responsibilities in this life. ${ }^{30}$

However, these practices are far removed from the life of the average rural Indian. Here, the issue of shame related to suicide will play a much larger influence. Hindu writings also have stories where suicide is glorified in situations where someone seeks to avoid shame or disgrace. ${ }^{17}$ Hindi movies have also frequently portrayed suicide as an option for avoiding a situation of shame. The issue of shame plays a large part in suicide, and it is imperative to understand this when considering prevention and intervention in suicides in India.

Shame related issues also explain the large number of Nepali patients seen in this study. In both India and Nepal, attempted suicide requires reporting to the police. The principle behind this is that it is the role of the state to protect people from taking their own lives, just as it is their role to protect people from taking the lives of others. ${ }^{31}$ To avoid this police report, the Nepali people come to India for treatment, and some Indians go across to Nepal, while others give Nepali addresses. This also contributes to the ongoing problem of under-reporting of suicides as families seek to find ways to avoid the shame suicide brings on the whole family. Until a person attempting suicide is seen as someone in need of help, instead of a person to be prosecuted, under reporting will continue.

Religiosity, rather than religion, is also important to consider and needs further examination. This study shows almost 50\% either carry out their religious practices on an occasional basis or not at all. Many do not find their religious practices meaningful. Lack of religious faith was seen to be a risk factor for suicide by Manorajitham. ${ }^{25}$ Religious rituals usually point to a deeper meaning of beliefs. How- ever, Hinduism is not a creedal religion and is more concerned about the correct practice of rituals. ${ }^{32}$ When people are in distress, the practice of rituals without deeper meanings may not be sufficient to provide them with the inner resources they need to prevent them from attempting suicide.

\section{Other factors related to suicide attempts}

The vast majority of suicide attempts occur by people consuming pesticides in contrast to South India where hangings, self-immolation, and drowning are more common. The most recent publication from the Haryana, North India, reports poisonings as $41.1 \%$, hangings as $36.8 \%$, and burns as $14.7 \% .^{22}$ No other data from Bihar is available for comparison. With a $92 \%$ rural population in East Champaran District, the easy availability and lack of safe storage of pesticides in this farming community could well explain the high rates of pesticide poisonings. ${ }^{1}$ Reasons for the low number of hanging and drowning suicides could include: 1) open wells are not common - the water table in Bihar is high and so closed tube wells largely suffice, 2) flimsy house structures with no fans (and no electricity) do not provide the strong support needed for a hanging, 3) a high population density of 1100 persons per square kilometre and open housing does not permit sufficient privacy to allow hanging. ${ }^{1}$

The media is often portrayed as an influence in putting the thought of suicide in people's minds. This appeared to be only a minor influence in this study. Movie halls are sparse in this rural area and television is lacking. However, "the local community grapevine" — the influence of knowing a neighbour or relative who has attempted suicide, is a major influence. When suicide prevention measures are being planned, this method of communication needs to be used to spread good messages instead of bad ones.

\section{Continued research and interventions}


Interventions are needed at many levels. At the level of public health, one of the interventions would be to ban Class I and II pesticides. This was done with good effect in Sri Lanka. ${ }^{33}$ Manorajitham et al. argue for a need to address the underlying causes of human suffering, including poverty, economic inequality, and lack of social justice. ${ }^{24}$ Although this could help alleviate psychosocial stress, it does not explain why the highest rates of suicide are in the Southern, more socio-economically advanced states of India.

Practical measures, such as secure storage of pesticides at a household or community level, can be initiated. ${ }^{34}$ Here in Bihar, where housing structures are very basic and lockable cupboards are unknown, education regarding safe storage of poisons would decrease the rates of both deliberate and accidental poisonings.

Although suicides in India are frequently considered to be impulsive in nature, it does not mean that a longer underlying history is irrelevant. The high rate of previous suicidal thoughts and the presence of poor family relationships suggest that the final family conflict may be "the straw that breaks the camel's back." Further investigation needs to be done to find the culturally appropriate cues indicating that people are considering suicide. Teaching families, teachers, and community health workers to be alert for suicidal behaviour could allow early interventions to prevent suicide.

The implementation of mental health services needs to be holistic in a number of ways.

First, while there is desperate need for psychiatrists, well trained family practitioners, social workers, mental health community nurses, specially trained community health volunteers, traditional healers, and religious leaders can all participate in providing care and community education. ${ }^{35-38}$

Second, preventative teaching, as well as interventional care, needs to be holistic. Topics such as alcohol abuse, domestic violence, and the value of women must be included. Third, people need to be treated not just from a biological perspective but as physical, social, psychological, and spiritual individuals, relating within their family, community, and the environment. ${ }^{38,39}$

A major focus of preventative work needs to be with young people. Training in life skills, such as handling relational conflict and stress particularly in family situations, could be used in both school settings and in the community. The value of every human life, especially the value given to women, is an intrinsic characteristic of the Christian faith. Using these values as a basis for intervention provides a sense of worth and hope to those badly in need of it. There is also an important role to be played in mentoring young people through their teenage years and into healthy families. Building strong, caring families is an essential intervention in decreasing the problem of suicide in India.

\section{References}

1. Bihar Population Census 2011. [Internet]. [Cited 2015 Jan 23]. Available from: http://www.census2011.co.in/census/state/bihar.html

2. India Census. Population by Religion in Bihar. [Internet]. [Cited 2015 Jan 23]. Available from: http://www.censusindia.gov.in/Census_Data_2001/Ce nsus_data_finder/C_Series/Population_by_religious_ communities.htm

3. Bajpai P, Bhandari L, Singh A. Social and economic profile of India. [Internet]. New Delhi: Social Service Press; 2005. [Cited 2015 Jan 20].

4. Press Information Bureau. Uttar Pradesh, Bihar, Maharashtra among the states with large no. of people living below poverty line. [Internet]. Government of India, 3 July 2009. [Cited 2015 Jan 21]. Available from:

http://pib.nic.in/newsite/erelease. $\operatorname{aspx}$ ?relid=49731

5. Annual Health Survey 2010-11, Bihar.

[Internet].[Cited 2014 June 30]. Office of the

Registrar General and Census Commissioner, India; 2012. Available from: www.jsk.gov.in/ahs10/bihar.pdf

6. Department of Health, Government of Bihar. Monitorable goals of the $11^{\text {th }}$ plan. [Internet]. 2009. [Cited 2015 Jan 23]. Available from: http://planning.bih.nic.in/Ppts/PR-05-02-12-2009.pdf 
7. State Health Society, Bihar. Manpower management. [Internet]. 2008. [Cited 2015 Jan 23]. Available at:

http://www.statehealthsocietybihar.org/manpowermgmt.html

8. Thirunavukarasu M, Thirunavukarasu P. Training and national deficit of psychiatrists in India - a critical analysis. Indian J Psychiatry. 2010;52:583-8. http://dx.doi.org/10.4103/0019-5545.69218

9. Soman CR, Safraj V, Kutty R, Vijayakumar K, Ajayan K. Suicide in South India: A communitybased study in Kerala. Indian J Psychiatry. 2009;51:261-4. http://dx.doi.org/10.4103/0019$\underline{5545.58290}$

10. Aaron R, Joseph A, Abraham S, Muliyil J, George $\mathrm{K}$, Prasad J, et al. Suicides in young people in rural southern India. Lancet. 2004;363:1117-8. http://dx.doi.org/10.1016/S0140-6736(04)15896-0

11. Joseph A, Abraham S, Muliyil JP, George K, Prasad J, Minz S, et al. Evaluation of suicide rates in rural India using verbal autopsies, 1994-9. BMJ. 2003;326:121-2.

12. Das A. Farmers' Suicide in India: implications for public mental health. Int J Soc Psychiatry.

2009;57:21. Available from:

http://isp.sagepub.com/content/57/1/21.full.pdf+html

13. Vijaykumar L. Suicide and its prevention: the urgent need in India. Indian J Psychiatry. 2007;49:814. http://dx.doi.org/ 10.4103/0019-5545.33252

14. Hirsch K. A review of the literature on rural suicide - risk and protective factors, incidence, and prevention. Crisis. 2006;27:189-99.

http://dx.doi.org/10.1027/0227-5910.27.4.189

15. Alston M. Rural male suicide in Australia. Soc Science Med 2010;74:515-22.

http://dx.doi.org/10.1016/j.socscimed.2010.04.036

16. Caldwell TM, Jorm AF, Dear KBG. Suicide and mental health in rural, remote and metropolitan areas in Australia. MJA. 2004;181:7. [Suppl- Depression: Reducing the burden]. Available from: https://www.mja.com.au/journal/2004/181/7/suicideand-mental-health-rural-remote-and-metropolitanareas-australia

17. Radhakrishnan R, Andrade C. Suicide: an Indian perspective. Indian J Psychiatry [serial online] 2012 [cited 2015 Mar 12];54:304-19. Available from: http://www.indianjpsychiatry.org/text.asp?2012/54/4/ $\underline{304 / 104793}$

18. Patel V, Ramasundarahettige C, Vijayakumar L, Thakur JS, Gajalakshmi V, Gururaj G, et al. Mortality in India: a nationally representative survey. Lancet. 2012; 379:2343-51. http://dx.doi.org/10.1016/S01406736(12)60606-0

19. World Health Organisation. Major (ICD-10) Depression Inventory. Psychiatric Research Unit, WHO Collaborating Centre in Mental Health. Undated. [Cited 2013 December 17]. Available from: http://www.cure4you.dk/960/MDI\%20Major\%20Dep ression\%20Inventory\%20-\%20English.pdf

20. Vassarstats: Website for Statistical Calculation. Available from: http://www.vassarstats.net [Cited 2013 Dec 10]

21. Gouda MRN, Rao SM. Factors related to attempted suicide in Davangere. Indian J Community Med. 2008;33:15-8. Available from: http://www.ncbi.nlm.nih.gov/pubmed/19966990

22. Salve H, Kumar R, Sinha S, Krishnan A. Suicide an emerging health problem: Evidence from rural Haryana. Indian J Public Health. 2013; 57:40-42. http://dx.doi.org/10.4103/0019-557X.111373

23. Gajalakshmi V, Peto R. Suicide rates in rural Tamil Nadu, South India: verbal autopsy of 39000 deaths in 1997-98. Int J Epidemiol. 2007;36:203-7. http://dx.doi.org/10.1093/ije/dyl308

24. Department of Agriculture. [Internet]. Government of India. [Last updated March 9, 2015, Cited 2015 March 9]. Available from: http://krishi.bihar.nic.in

25. Manoranjitham SD, Rajkumar AP, Thangadurai P, Prasad J, Jayakaran R, Jacob KS. Risk factors for suicide in rural south India. BJP 2010;196:26-30. http://dx.doi.org/10.1192/bjp.bp.108.063347

26. Living works. applied suicide intervention skills training (ASIST) workbook. Australia; Living Works Education; 2007.

27. Narang RL, Mishra BP, Mohan N. Attempted suicide in Ludhiana. Indian J Psychiatry. 2000;42:837.

28. Cavanagh JTO, Carson AJ, Sharpe M, Lawrie SM. Psychological autopsy studies of suicide: a systematic review. Psychol Med. 2003;33:395-405. http://dx.doi.org/10.1017/S0033291702006943 
29. Murthy RS. Approaches to suicide prevention in Asia and the Far East. In: Hawton K, van Heerington $\mathrm{K}$, editors. International handbook on suicide and attempted suicide. Chichester, England: Wiley; 2000. p630-43.

30. Jayaram V. About suicides in Hinduism. [Internet]. [Undated]. [Cited 2015 Feb 5]. Available from: http://www.hinduwebsite.com/hinduism/h_suicide.as p

31. Khan D, Lester D. Efforts to decriminalize suicide in Ghana, India and Singapore. [Internet]. Suicidol Online 2013;4:96-104. Available from: http://www.suicidology-online.com

32. Ramachandra V. Faiths in conflict - Christian integrity in a multicultural world. Leicester, England: IVP; 1999.

33. Gunnel D, Fernando R, Hewagama M, Priyangika WDD, Konradsen F, Eddleston M. The impact of pesticide regulation on suicide in Sri Lanka. Int $\mathbf{J}$ Epidemiol. 2007;36:1235-42. http://dx.doi.org/10.1093/ije/dym164

34. Weerasinghe M, Ravi Pieris R. Eddleston M, van der Hoek W, Dawson A, Konradsen F. Safe storage of pesticides in Sri Lanka - identifying important design features influencing community acceptance and use of safe storage devices. BMC Public Health.
2008;8:276. http://dx.doi.org/10.1186/1471-2458-8$\underline{276}$

35. Weiss MG, Isaac M, Parker SR, Chowdhury AN. Global, national and local approaches to mental health: examples from India. Trop Med Int Health. 2001;1:4-23. http://dx.doi.org/10.1046/j.13653156.2001.00670.x

\section{Hanlon C, Luitel NP, Kathree T, Murhar} V, Shrivasta S, Medhin G, et al. Challenges and opportunities for implementing integrated mental health care: a district level situation analysis from five lowand middle-income countries PLoS ONE. 9(2): e88437.

http://dx.doi.org/10.1371/journal.pone.0088437

37. Patel V, Goel DS, Desai R. Scaling up services for mental and neurological disorders in low-resource settings. Int Health. 2009;1:37-44. Available from: http://dx.doi.org/10.1016/j.inhe.2009.02.002

38. Allen EA. Caring for the whole person. California: MARC; 1995.

39. Webb D. Thinking about suicide - contemplating and comprehending the urge to die. Exclusion and Embrace - Conversations about Spirituality and Disability Conference in Melbourne, Australia, 18-21 October 2001. [Internet] [Cited 2015 February 2]. Available from: http://thinkingaboutsuicide.org/

Peer Reviewed

Competing Interests: None declared.

Correspondence: Lois Armstrong, Duncan Hospital, a unit of Emmanuel Hospital Association, India loisjarmstrong@gmail.com

Cite this article as: Nair S, Armstrong LJ and Finny P. Family Conflict - The major underlying influence in suicide attempts in Northern Bihar, India. Christian Journal for Global Health (April 2014), 2(1):23-34.

(C) Nair S, et al. This is an open-access article distributed under the terms of the Creative Commons Attribution License, which permits unrestricted use, distribution, and reproduction in any medium, provided the original author and source are properly cited. To view a copy of the license, visit http://creativecommons.org/licenses/by/3.0/

$$
\text { www.cjgh.org }
$$

